\title{
Are apparent negative effects of feeding GM MON810 maize to Atlantic salmon, Salmo salar, caused by confounding factors?
}

\author{
Nini H. Sissener ${ }^{1 *}$, Gro-Ingunn Hemre ${ }^{1}$, Santosh P. Lall ${ }^{2}$, Anita Sagstad ${ }^{1}$, Kjell Petersen ${ }^{3}$, \\ Jason Williams ${ }^{2}$, Jens Rohloff ${ }^{4}$ and Monica Sanden ${ }^{1}$ \\ ${ }^{1}$ National Institute of Nutrition and Seafood Research, Postboks 2029 Nordnes, 5817 Bergen, Norway \\ ${ }^{2}$ Institute of Marine Biosciences, Halifax, Nova Scotia, Canada \\ ${ }^{3}$ Bergen Center for Computational Science (BCCS), The Computational Biology Unit (CBU), Bergen High Technology Centre \\ (HIB), Bergen, Norway \\ ${ }^{4}$ The Plant Biocentre (PBC), Department of Biology, Norwegian University of Science and Technology (NTNU), Trondheim, \\ Norway
}

(Received 10 August 2010 - Revised 29 November 2010 - Accepted 7 December 2010 - First published online 21 March 2011)

\section{Abstract}

The present study was conducted to follow up on apparent differences in growth, relative organ sizes, cellular stress and immune function in Atlantic salmon fed feed containing GM Bacillus thuringiensis maize compared with feed containing the non-modified parental maize line. Gene expression profiling on the distal intestinal segment and liver was performed by microarray, and selected genes were followed up by quantitative PCR (qPCR). In the liver, qPCR revealed some differentially regulated genes, including up-regulation of gelsolin precursor, down-regulation of ferritin heavy subunit and a tendency towards down-regulation of metallothionein (MT)-B. This, combined with the up-regulation of anti-apoptotic protein NR13 and similar tendencies for ferritin heavy chain and MT-A and -B in the distal intestine, suggests changes in cellular stress/antioxidant status. This corresponds well with and strengthens previous findings in these fish. To exclude possible confounding factors, the maize ingredients were analysed for mycotoxins and metabolites. The GM maize contained $90 \mu \mathrm{g} / \mathrm{kg}$ of deoxynivalenol (DON), while the non-GM maize was below the detection limit. Differences were also observed in the metabolite profiles of the two maize varieties, some of which seemed connected to the mycotoxin level. The effects on salmon observed in the present and previous studies correspond relatively well with the effects of DON as reported in the literature for other production animals, but knowledge regarding effects and harmful dose levels in fish is scarce. Thus, it is difficult to conclude whether the observed effects are caused by the DON level or by some other aspect of the GM maize ingredient.

Key words: GM: Bacillus thuringiensis maize: Mycotoxin: Microarray techniques

The use of GM plants as food and feed has been debated for more than two decades. As plant products are used to partially replace marine resources in fish feed production, the GM debate has also become part of fish farming. Availability of GM-free ingredients has become a challenge for the feed industry $^{(1,2)}$. Soyabean and maize are the most commonly grown GM plants, with 77 and $26 \%$ of the global acreage of these respective crops planted with GM varieties ${ }^{(3)}$.

The current technology used for genetic modification is based on random integration of the novel DNA into the plant genome $e^{(4)}$. This integration can cause rearrangements of both the transgenic construct and DNA at the insertion site (often causing instability in transgene expression), as well as genome-wide mutations ${ }^{(5-7)}$. These processes can cause unintended effects in the GM plant with altered levels of nutrients, anti-nutrients or unknown compounds, although unintended effects are not unique to GM plants and can occur in traditionally bred plants as well ${ }^{(8,9)}$, and such effects are screened for during the approval process of GM plants. Additionally, the novel protein itself may have toxic effects or elicit a harmful immunological response including allergic hypersensitivity ${ }^{(10)}$.

Cry proteins are expressed in many GM crops to make the plants resistant to insects. These proteins are naturally found in the soil bacterium Bacillus thuringiensis, hence are often referred to as $B t$-proteins or $B t$-toxins. These toxins bind to

Abbreviations: cDNA, complementary DNA; DON, deoxynivalenol; FDR, false discovery rate; GRASP, Genomics Research on All Salmonids Project; GSEA, gene-set enrichment analysis; HSP, heat shock protein; MT, metallothionein; qPCR, quantitative PCR; SAM, significance analysis of microarray; SOD, superoxide dismutase; SSC, saline-sodium citrate.

*Corresponding author: Dr N. H. Sissener, fax +475590 52 99, email nsi@nifes.no 
specific receptors in the mid-intestine of target insects, causing damage to the intestinal wall and resulting in their death ${ }^{(11)}$, although the different Cry proteins have slightly different properties and target different insects. The Norwegian Scientific Committee for Food Safety ${ }^{(12)}$ has questioned the safety of $B t$-toxins and identified knowledge gaps. Studies in mice using isolated Cry1Ac protoxin from B. thuringiensis ${ }^{(13)}$ and recombinant Cry1Ac from transgenic Escherichia coli ${ }^{(13-15)}$ have indicated that this protein binds to the intestinal mucosa, where it induces in vitro hyperpolarisation of the intestinal tissue and stimulates antibody production. If transgenic $B t$-protein (Cry1Ab in this case) causes similar changes in salmon, this may help explain differences in haematology, levels of stress-related proteins ${ }^{(16)}$, intestinal weight and changes in intestinal nutrient transport ${ }^{(17)}$ observed in salmon fed MON810 maize. MON810 is one of several modification events producing $B t$-maize and has a gene-introduced coding for the Cry $1 \mathrm{Ab}$ protein. Questions regarding the safety of $B t$-maize have also been raised for other species. A 90 d rat study with $B t$-maize (MON863, expressing Cry3Bb1) conducted by Monsanto ${ }^{(18)}$ was reanalysed by others claiming signs of hepatorenal toxicity ${ }^{(19)}$. However, this reanalysis was discarded by the European Food Safety Authority ${ }^{(20)}$ and others $^{(21)}$, concluding that the observed effects were spurious occurrences without biological relevance. In a three-generational study performed on rats with Bt-corn (modification event and type of Cry protein not specified), histopathological changes in the kidney and liver were observed ${ }^{(22)}$

The outcome of feeding trials with GM ingredients may be limited with respect to a restricted and biased selection of parameters investigated $^{(8,23)}$. Molecular profiling methods such as proteomics and transcriptomics may increase the chances of identifying potential effects of GM feeds and may help reveal the mechanisms behind those effects. Limited work has been conducted in this area, but proteomic profiling of the liver has been used in the assessment of GM soya in feed for salmon ${ }^{(24)}$, and suppression subtractive hybridisation complementary DNA (cDNA) libraries have been constructed for salmon fed GM soya and maize ${ }^{(25,26)}$. Microarray is another profiling technique that might be useful in evaluating the effects of GM feed ingredients. The Genomics Research on All Salmonids Project (GRASP) has produced a cDNA array of 16000 genes from salmon and trout expressed sequence tags and contigs ${ }^{(27)}$, which can provide novel insight into various biological systems of salmon.

The presence of confounding factors is always an issue when testing diet ingredients; thus it is crucial that the diet ingredients are sufficiently characterised, so that possible differences can be taken into account during diet formulation if possible, or at least when interpreting the results of the trial. There are numerous different mycotoxins that can potentially be present in maize, and there is limited knowledge regarding the effects of these on fish. Mycotoxins are secondary metabolites of moulds, chemically stable, not inactivated by heat treatment ${ }^{(28)}$, and thus can be assumed to survive standard processing of fish feeds.

The aim of the present study was to investigate potential differences in the gene expression profile in the intestine, as the first site of exposure to the feed ingredients, and the liver, as the main metabolic organ, between Atlantic salmon fed feeds containing GM MON810 maize and the near-isogenic non-modified maize, respectively. This investigation is part of a larger feeding trial, from which a range of health and performance-related parameters have been reported previously $^{(16,17)}$. Furthermore, characterisation of the diet ingredients was extended with analyses of mycotoxins and metabolite profiling to reveal potential differences between the GM and non-GM maize.

\section{Materials and methods}

\section{Ingredients, diets and feeding}

We made two experimental diets, containing either the GM maize (modification event MON810) or the untransformed, near-isogenic parental line (non-GM maize). Both were kindly supplied by the Monsanto Company (St Louis, MO, USA). The maize ingredients were dried and ground before feed production, and the inclusion level of maize in the diets was $30 \%$. Proximate analyses of the maize ingredients, as well as analysis of phytate content, are reported by Hemre et $a l .{ }^{(17)}$. Screening for herbicide residues in these maize ingredients revealed no content above the detection level, neither in the GM nor in the non-GM maize ${ }^{(29)}$. The mycotoxins aflatoxin $B_{1}$, aflatoxin $B_{2}$, aflatoxin $G_{1}$, aflatoxin $\mathrm{G}_{2}$ and ochratoxin A were determined quantitatively using HPLC-fluorescence, while deoxynivalenol (DON), HT-2 toxin, nivalenol, T-2 toxin and zearalenone were determined quantitatively using liquid chromatography-MS. All mycotoxin analyses were performed by the Institute of Veterinary Science, Oslo, Norway.

Low-temperature quality fishmeal and fish oil supplied most of the protein and lipid in the diets. National Research Council $^{(30)}$ recommendations were followed for vitamin and mineral additions. Rovimix, which contains $8 \%$ astaxanthin, was added as a pigment source. The diets were made at the Nofima Feed Technology Centre (Bergen, Norway). Formulation and analysed composition, including a selection of vitamins and minerals (which have also been published previously ${ }^{(17)}$ ), of the diets are given in Table 1 . The diets were compositionally similar in all analysed nutrients. Each diet was fed to triplicate tanks in excess, from automated feeders running in intervals of $20 \mathrm{~s}$ intervened by $200 \mathrm{~s}$ (05.00 to 08.00 hours and 14.00 to 03.00 hours).

\section{GC-MS-based metabolite profiling}

Samples of non-GM and GM maize ( $n$ 3) were ground to powder with a mortar and pestle, and $300 \mathrm{mg}$ were transferred to $2 \mathrm{ml}$ round-shaped Eppendorf tubes. Then, $400 \mu \mathrm{l}$ of $100 \%$ methanol containing the internal standard ribitol $(20 \mu \mathrm{g} /$ $400 \mu \mathrm{l})$ were added to the tubes and vortexed. Samples were then treated for $15 \mathrm{~min}$ at $70^{\circ} \mathrm{C}$ in a shaking incubator (200 rpm). After the samples had been cooled down to ambient temperature, $200 \mu \mathrm{l} \mathrm{CHCl}_{3}$ were added, and the samples were vortexed for $10 \mathrm{~s}$. Then, $400 \mu \mathrm{l}$ distilled water were 
Table 1. Formulation and chemical composition of the two experimental diets $(\mathrm{g} / \mathrm{kg})$

\begin{tabular}{lcc}
\hline Diet & Non-GM maize & GM maize \\
\hline Formulation $(\mathrm{g} / \mathrm{kg})$ & & \\
$\quad$ Fishmeal & 514 & 515 \\
Non-GM maize & 300 & \\
GM maize & & 300 \\
Fish oil & 171 & 170 \\
Yttrium oxide & $0 \cdot 1$ & $0 \cdot 1$ \\
Vitamins and minerals* & 15 & 15 \\
Proximate analysis $(\mathrm{g} / \mathrm{kg})$ & & \\
DM & 932 & 930 \\
Protein† & 398 & 395 \\
Lipid† & 225 & 228 \\
Starch & 161 & 166 \\
Ash† & 94 & 92 \\
Residueł & 54 & 49 \\
Gross energy§ (kJ/g) & 21.2 & $21 \cdot 2$ \\
\hline
\end{tabular}

* Vitamins and minerals were added according to National Research Council recommendations ${ }^{(30)}$.

† Fatty acid composition ( $\mathrm{g} / \mathrm{kg}$ of total fatty acids) and total amino acids were equivalent in the two diets. Ca varied from 18.6 to $19.0 \mathrm{~g} / \mathrm{kg}, \mathrm{P}$ from 12.7 to $13.1 \mathrm{~g} / \mathrm{kg}, \mathrm{Zn}$ from 206 to $214 \mathrm{mg} / \mathrm{kg}, \mathrm{Fe}$ from 154 to $166 \mathrm{mg} / \mathrm{kg}$ and Se from 1.4 to $1.6 \mathrm{mg} / \mathrm{kg}$. Vitamin $A_{1}$ $(21.2 \mu \mathrm{g} / \mathrm{g})$, vitamin $A_{2}(1 \mu \mathrm{g} / \mathrm{g}), \alpha$-tocopherol $(159-174 \mu \mathrm{g} / \mathrm{g})$ and thiobarbituric acid-reactive reagents $(50-55 \mathrm{nmol} / \mathrm{g})$ were added. B vitamins were not analysed but added according to National Research Council recommendations ${ }^{(30)}$.

‡ Residue was calculated as 1000 - (moisture + protein + lipid + starch + ash).

$\S$ Gross energy was calculated according to $\operatorname{Tacon}^{(101)}$.

added, and the samples were again vortexed for $15 \mathrm{~s}$ at full speed. The tubes were placed in a centrifuge for $10 \mathrm{~min}$ at $13000 \mathrm{rpm}$ at $4^{\circ} \mathrm{C}$. The supernatant $(300 \mu \mathrm{l})$ was transferred to $1.5 \mathrm{ml}$ round-bottomed Eppendorf tubes and further dried in a speed vacuum without heating. The dried residue was re-dissolved in $80 \mu \mathrm{l}$ of methoxyamine hydrochloride $(20 \mathrm{mg} / \mathrm{ml})$ in pyridine and derivatised at $30^{\circ} \mathrm{C}$ for $90 \mathrm{~min}$ in a shaking incubator $(200 \mathrm{rpm})$. Finally, the samples were treated with $80 \mu \mathrm{l}$ of $N$-methyl- $N$-(trimethylsilyl)trifluoroacetamide and placed at $37^{\circ} \mathrm{C}$ in a shaking incubator $(200 \mathrm{rpm})$ for $30 \mathrm{~min}$. The samples were transferred to $1.5 \mathrm{ml}$ of autosampler vials with glass inserts and subjected to metabolite profiling by GC-MS. An Agilent 6890/5975 GC-MS system was used for all analyses. Sample volumes of $1 \mu \mathrm{l}$ were injected with a split ratio of 25:1. GC separations were carried out on a HP-5MS capillary column (inner diameter $30 \mathrm{~m} \times 0.25 \mathrm{~mm}$ and film thickness $0.25 \mu \mathrm{m})$. Injection temperature was $230^{\circ} \mathrm{C}$, and the interface was set to $250^{\circ} \mathrm{C}$. The carrier gas was He at a constant flow rate of $1 \mathrm{ml} / \mathrm{min}$. The GC temperature programme was held isothermically at $70^{\circ} \mathrm{C}$ for $5 \mathrm{~min}$, ramped from 70 to $310^{\circ} \mathrm{C}$ at a rate of $5^{\circ} \mathrm{C} / \mathrm{min}$ and finally held at $310^{\circ} \mathrm{C}$ for $7 \mathrm{~min}$ (analysis time: $60 \mathrm{~min}$ ). The MS source was adjusted to $230^{\circ} \mathrm{C}$, and a mass range of $m / z 50-700$ was recorded. All mass spectra were acquired in electron impact ionisation mode. Chromatogram visualisation and peak area integration were carried out using Agilent ChemStation software (Agilent Technologies, Waldbronn, Germany). For mass spectra evaluation and peak identification, AMDIS software (version 2.64; National Institute of Standards and Technology, Boulder, CO, USA) was used in combination with the following mass spectral libraries: a NIST05 database and a target TMS database
(Max-Planck Institute for Molecular Plant Physiology, Golm, Germany). Detected metabolites were measured using peak area integration, assessed quantitatively based on the internal standard ribitol and finally expressed as $\mathrm{mg} / \mathrm{kg}$ dry weight.

\section{Experimental animals and rearing conditions}

The feeding trial took place at the Feed Technology Centre, Nofima (Austevoll, Norway). Fish were acclimatised to rearing conditions for 2 weeks before being randomly distributed into six dark-green fibreglass tanks $(1.5 \times 1.5 \times 0.9 \mathrm{~m})$, each containing forty-five fish. Initial weight averaged 155 (SD 3) g. The feeding trial lasted for $82 \mathrm{~d}$, from 17 June until 9 September 2004. The fish were exposed to continuous light, salinity varied between 31 and $32 \mathrm{~g} / 1$, and the temperature averaged $8(\mathrm{SD} 0.5)^{\circ} \mathrm{C}$. A flow-through system of $50-55$ litres $/ \mathrm{min}$ ensured high water quality, maintaining average water oxygen content at $7.8 \mathrm{mg} / \mathrm{l}$ ( $88 \%$ saturation). The trial was approved by the National Animal Research Authority in Norway.

\section{Sampling procedure}

Fish were not deprived of feed before sampling, as various feed effects on the intestine, such as soyabean meal-induced inflammation, intestinal mass and enzyme activities, have been shown to decrease rapidly when salmon were not fed $^{(31,32)}$. The fish were pre-anaesthetised with Aqui- $S^{\mathrm{TM}}$ isoeugenol (540 g/1; Scan Aqua, Årnes, Norway) and thereafter fully anaesthetised with metacainum $\left(50 \mathrm{mg} / \mathrm{l}\right.$; MS-222 ${ }^{\mathrm{TM}}$; Norsk Medisinaldepot AS, Oslo, Norway). Tissues from the liver and distal intestine were immediately placed in RNAlater ${ }^{\mathrm{TM}}$ (Ambion, Huntingdon, UK) and stored as recommended by the manufacturer.

\section{RNA isolation and quality control}

Total RNA from the liver and distal intestinal samples was extracted using the same procedure as described by Sagstad et l. $^{(16)}$. Briefly, total RNA was isolated from 50 to $70 \mathrm{mg}$ of tissue in TRIzol reagent (Invitrogen Life Technologies, Grand Island, NY, USA) using a phenol-chloroform extraction method. Liver tissue was homogenised using MagNA Lyser Green Beads (Roche, Mannheim, Germany) and a MM301 shaker machine (Retsch Norge AS, Haan, Germany) at full speed for $4 \mathrm{~min}$, while intestinal tissue was homogenised with a Polytron (Kinematica, Bohemia, NY, USA) without the use of beads. The final samples were diluted in 50-300 $\mu \mathrm{l}$ RNase-free double-distilled water (MilliQ Biocel; Millipore Corp., Bedford, MA, USA) and treated with the DNA-free ${ }^{\mathrm{TM}}$ kit (Ambion) according to the manufacturer's instructions, before being stored at $-80^{\circ} \mathrm{C}$. Quantity and quality of RNA samples were assessed with the NanoDrop ${ }^{\circledR}$ ND-1000 UV-Vis Spectrophotometer (NanoDrop Technologies, Wilmington, DE, USA) and the Agilent 2100 Bioanalyser (Agilent Technologies, Palo Alto, CA, USA) using the RNA 6000 Nano LabChip ${ }^{\circledR}$ kit (Agilent Technologies). The quality of the RNA samples (optical density (OD) $260 / \mathrm{OD}_{280} 1 \cdot 8-2 \cdot 00$, RNA integrity 
number (RIN) number 8-10) was found sufficient for labelling and hybridisation. Samples were divided into two aliquots, one for microarray and one for quantitative PCR (qPCR) analyses.

\section{Microarray design}

The microarray experiment was designed to comply with the Minimum Information About a Microarray Experiment guidelines ${ }^{(33)}$. Minimum Information About a Microarray Experiment compliant data have to be uploaded to the Array Express database (accession no. E-TABM-1056). A common reference design was utilised with each individual sample hybridised together with a common reference sample to the cGRASP version 2.0 16K cDNA microarray. Total RNA from fish fed the control diet (non-GM) was pooled to make an RNA reference pool (nine fish), with each fish represented equally. The reference RNA was hybridised against individual fish in the control diet (non-GM, $n$ 9, only intestinal and liver samples were not hybridised due to time constraints) and the treatment diet (GM, $n$ 9, both intestine and liver). A total of eighteen arrays were analysed for the intestine, and nine arrays for the liver (Fig. 1).

\section{RNA labelling and microarray hybridisation}

Total RNA $(10-20 \mu \mathrm{g})$ was transcribed into cDNA and indirectly labelled with fluorescent dye using aminoallyland aminohexyl-modified nucleotides (SuperScript ${ }^{\mathrm{TM}}$ Indirect cDNA Labelling System; Invitrogen). The pooled reference RNA was always labelled with Cy3 (Amersham Biosciences, Piscataway, NJ, USA), and RNA from individual fish was labelled with Cy5. After labelling, reference and individual samples were paired into one tube according to yield and

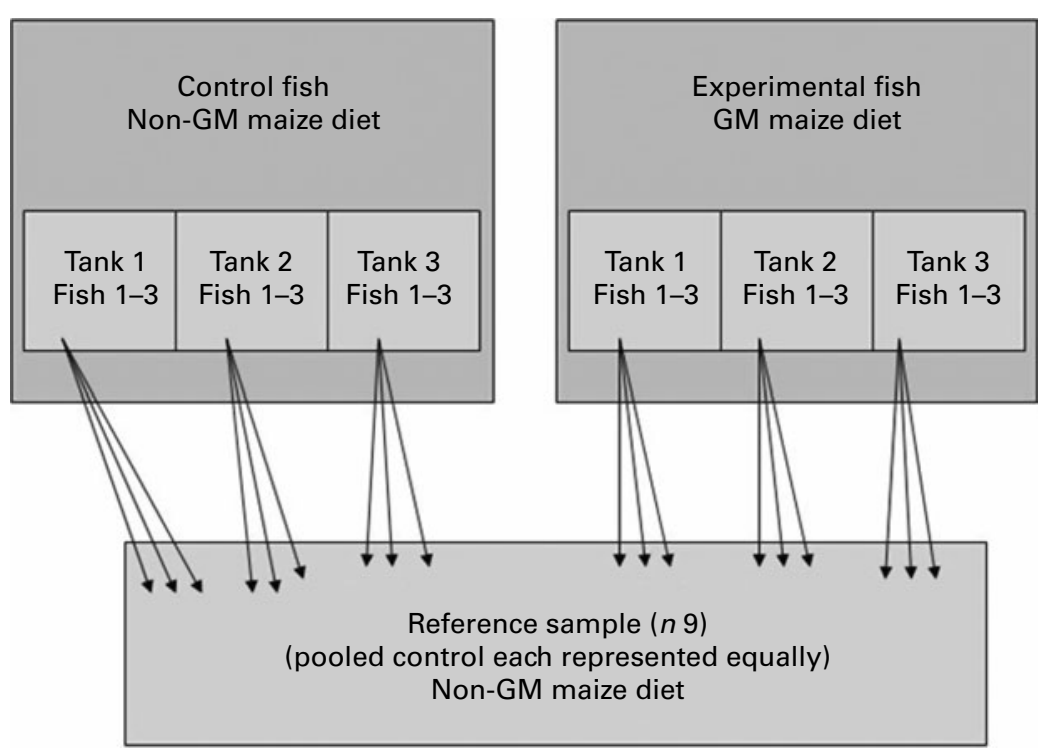

Fig. 1. Common reference design was used for the microarray hybridisations. For the intestinal samples, both the nine samples from fish fed the GM maize diet (three from each of three tanks) and the nine samples from fish fed the non-GM diet were hybridised against the reference sample, which was a pool of all nonGM samples. For the liver samples, only sample the fish fed the GM maize diet were hybridised against the reference sample. dye incorporation, combined and concentrated by a vacuum concentrator (Vacufuge ${ }^{\mathrm{TM}}$; Eppendorf, Hamburg, Germany). Before hybridisation, slides were post-print processed and pre-hybridised. The post-print process was performed by washing twice in $0.2 \%$ SDS for $5 \mathrm{~min}$, five times in Milli-Q water for $1 \mathrm{~min}$ and then the slides were dried for $2 \mathrm{~min}$ by centrifugation. Microarrays were pre-hybridised for 90-120 min in 5 $\times$ saline-sodium citrate (SSC), $0 \cdot 1 \%$ SDS, $3 \%$ bovine serum albumin (fraction $\mathrm{V}$ ) at $30^{\circ} \mathrm{C}$ followed by three quick washes (20s) in Milli-Q water and immediately thereafter dried by centrifugation. The hybridisation mix was composed of $4 \mu \mathrm{l}$ of LNA dT blocker (Genisphere, catalogue no. CW3920), $46 \mu \mathrm{l}$ of DIG Easy Hyb (Roche catalogue no. 1796.895) and $10 \mu \mathrm{l}$ of labelled cDNA resuspended in nuclease-free water (catalogue no. 9939; Ambion), giving a total volume of $60 \mu \mathrm{l}$. Microarray hybridisations were run in the dark under HybriSlips hybridisation covers (Erie Scientific, Portsmoth, NH, USA) in slide hybridisation chambers (Corning Inc., Corning, NY, USA) submerged in a $30^{\circ} \mathrm{C}$ water-bath for $16-18 \mathrm{~h}$. Coverslips were floated off at $30^{\circ} \mathrm{C}$ in $2 \times \mathrm{SSC}$, $0 \cdot 1 \%$ SDS for $20 \mathrm{~min}$. Arrays were washed twice in $2 \times$ SSC, $0 \cdot 1 \%$ SDS for $10 \mathrm{~min}$ at room temperature, twice in $1 \times$ SSC for $10 \mathrm{~min}$ and twice in $0.1 \times$ SSC for $10 \mathrm{~min}$ at room temperature. The slides were dried by centrifugation for $2 \mathrm{~min}$.

Fluorescent images of hybridised arrays were acquired immediately at $10 \mu \mathrm{m}$ resolution using a ScanArray ${ }^{\mathrm{TM}} 5000 \mathrm{XL}$ Microarray Acquisition scanner (Packard BioChip Technologies, Billerica, MA, USA). Cy3 and Cy5 cyanine fluorophores were excited at 543 and $633 \mathrm{~nm}$, respectively, and the same laser power (100\%) and photomultiplier tube settings (80-90\%) were used for all slides in the present study. The photomultiplier tube voltage was adjusted for each slide by doing a line scan at $50 \mu \mathrm{m}$ resolution. 
Pre-processing, filtration and normalisation of microarray data

The images were processed using Gene Pix version 5.1 at the NMC core Facility Laboratory, before the data were filtered and normalised using J-Express Pro version 2.8 ${ }^{(34)}$ (www.molmine.com, Bergen, Norway). The foreground signal intensity values for each channel were extracted from the data files, and all flagged and control spots or spots saturated in either channel were filtered out before the data were normalised using the global lowess $\operatorname{method}^{(35)}$, which performs local background correction to adjust spot intensities. After normalisation, weak spots with a foreground signal of less than the background plus 1.5 standard deviations were filtered out. All arrays were compiled into a single expression profile data matrix containing the log ratios of the two foreground signal intensities, disregarding rows with more than $40 \%$ missing values, before replacing missing values using the LSimpute adaptive method ${ }^{(36)}$. Finally, samples were scale-normalised to make the distribution of log ratios comparable ${ }^{(37)}$.

\section{Microarray data analysis}

The scale-normalised intestinal data were then subjected to correspondence analysis ${ }^{(38)}$ and significance analysis of microarrays (SAM) ${ }^{(39)}$, both implemented in J-Express 2009 (Molmine, Bergen, Norway). The two-class, unpaired SAM was run with 400 permutations to look for differentially expressed genes on a gene-by-gene basis. Furthermore, gene-set enrichment analysis (GSEA) ${ }^{(40)}$ was conducted to identify differentially expressed gene sets. The gene sets were created on the basis of Gene Ontology (Gene Ontology Consortium; www.geneontology.org), by mapping the Gene Ontology annotations in the cGRASP version 2.0 annotation file (dated February 2008) to the Gene Ontology accession numbers in the Gene Ontology OBO file dated 9 September 2009. The analysis was run with probes collapsed to genes, so that each gene would contribute equally to the statistical analysis. Both gene and sample permutations were tried with 10000 iterations. As an alternative method to identify individual regulated genes, the rank product procedure was run with 1000 permutations.

The liver data could not be analysed statistically in J-Express, due to limitations in the design as described earlier with only the nine GM samples hybridised to the non-GM reference pool. In order to extract information from this dataset and use it to select potentially interesting genes to follow up by qPCR, the whole gene list with intensity values for each sample was copied into Excel. For each gene, the average intensity across all samples, standard deviation and CV were calculated. The list was sorted by average intensity, and 'genes of interest' were selected near the top and the bottom of the list, under the rationale that these genes must be the ones most differentially regulated between the diet groups. Only genes with a relatively low CV (as large individual variation in a gene would make it less likely to identify significant differences) and consistency in the direction of regulation (e.g. that ideally nine out of nine samples all had negative or positive intensity values) were selected.

After analysing the intestinal data, it became apparent that some of the differences observed might be due to chips being hybridised on different days or the different batches of chips used, rather than diet effects (these observations are further described in the Results section). As chip batches and hybridisation days had not been properly randomised across diet groups, such effects would be difficult to distinguish from diet effects. Consequently, the same approach as for the liver samples was attempted to avoid the problem of possible day and batch effects between the two diet groups.

\section{Quantitative PCR}

For verification, some genes that were selected based on the microarray results were analysed by real-time qPCR. Samples from the same individual fish as in the microarray analysis were used, as well as some additional samples of high-quality RNA from the same tanks (totally nine non-GM and eleven GM samples from the intestine, and thirteen liver samples from each diet group). Potential reference genes were chosen from the literature: elongation factor $1-\alpha^{(41)}$, heat shock protein (HSP) 90B, $\beta$-actin ${ }^{(42)}$, acidic ribosomal phosphoprotein $^{(43)}$ and RNA polymerase $1^{(44)}$. For the target genes, primers were designed using Primer Express ${ }^{\circledR} 2.0$ (Applied Biosystems, Foster City, CA, USA) and tested by one-step RT-PCR (Qiagen, Hilden, Germany) and agarose gel electrophoresis to confirm a single amplification product of the expected size. All primer (Invitrogen, Oslo, Norway) sequences are given in Table 2 and were designed to be within the protein-coding region of the mRNA sequence.

Constant amounts of $250 \mathrm{ng}$ RNA were reverse transcribed to cDNA on a GeneAmp ${ }^{\circledR}$ PCR 9700 machine (Applied Biosystems), using the TaqMan $^{\circledR}$ reverse transcriptase kit with oligo(dT) primers (Applied Biosystems) in $30 \mu$ l of reaction volume. Samples were run in triplicate wells, and one ninety-six-well cDNA plate was made for the intestinal and one for the liver samples. Each plate contained a dilution curve (from a pooled sample) for the determination of amplification efficiency, in addition to non-template and nonamplification controls. For real-time PCR, SYBR ${ }^{\circledR}$ Green I Mastermix (Roche), forward and reverse primers and cDNA were mixed in 384-well plates using a Biomek ${ }^{\circledR} 3000$ Laboratory automation workstation (Beckman Coulter, Fullerton, CA, USA). Thermal cycling was performed on a LightCycler ${ }^{\circledR} 480$ System (Roche Applied Science, Indianapolis, IN, USA) according to the following protocol: pre-incubation at $95^{\circ} \mathrm{C}$, forty-five cycles of amplification with 10, 20 and $30 \mathrm{~s}$ at 95, 60 and $72^{\circ} \mathrm{C}$, respectively. Finally, melting curve analysis was carried out between 65 and $95^{\circ} \mathrm{C}$ to confirm the presence of a single amplified product.

\section{Quantitative PCR data analysis}

Cycle threshold values were calculated using the second maximum derivative method in LightCycler ${ }^{\circledR}$ software. Efficiency was determined by the formula $E=10^{\wedge}(-1 /$ slope $)$, with the 
Table 2. Primer sequences and GenBank accession numbers for the sequences from which the primers were designed

\begin{tabular}{|c|c|c|c|}
\hline Gene & Forward primer & Reverse primer & Accession number \\
\hline Elongation factor $1 \mathrm{a}$ & ССССТCCAGGACGTTTACAAA & CACACGGCCCACAGGTACA & AF321836 \\
\hline$\beta$-Actin & CCAAAGCCAACAGGGAGAAG & AGGGACAACACTGCCTGGAT & BG933897 \\
\hline \multicolumn{4}{|l|}{ Heat shock protein $90 \mathrm{~B}$} \\
\hline RPL 1 & ACTATGGCTGTCGAGAAGGTGCT & TGTACTCGAACAGTCGTGGGTCA & CB516726 \\
\hline Retinoic acid receptor (retinoid X receptor $\gamma$ ) & GGTCTGGGTACTTGGCTTTGG & CGAGCCATCGTCCTCTTCAA & CB514936 \\
\hline High-affinity $\mathrm{Cu}$ uptake protein 1 & ACGTGGAGCTGCTGTTTGC & AGGAACTCCCTGCCGATCTT & BT059358 \\
\hline Splicing factor, arginine/serine-rich 16 & CCTGGACTTCATACCCACCTACA & TGGCAAAGTCGTTCTGCACTA & NM_001140100 \\
\hline Anti-apoptotic protein NR13 & GGTGGGAGACGGACAGATGA & CAGGCCCATGCCATTACC & NM_001139822 \\
\hline Cu chaperone for superoxide dismutase & GACGTGCTGCACAAAAATGG & CTGCACGCCTGGTTTTCCT & NM_001140314 \\
\hline Tight junction protein ZO-2 & CGGTTGGCAGAGTTCATTTTTAC & CTCCGACTCCGAACCTGATG & CB511875 \\
\hline Claudin-3 & TCAGCCAACAGCATCATCATG & ACCCCCCAATGAGGAGAAAA & BT048428 \\
\hline Gelsolin precursor & ССTCСTCCTACGGCCAGTTC & TCATCCTGGGTGCACTTCAG & BT072088 \\
\hline Ferritin, heavy chain & CAGGTGAGACAGAACTTCCATCAG & CCTGGTCATCACGATCAAAGTAAT & ВT048149 \\
\hline $\mathrm{Hb}$ subunit $\alpha$ & GCTCTGCCCCAGTCAAGAAG & AGCTTGAAGGCGTGCAGATC & BT059538 \\
\hline Metallothionein A & TGCATGCACCAGTGGTAAGAA & GCCTCACTGACAACAGCTGGTA & BT059876 \\
\hline Metallothionein B & TCTTGCAACTGCGGTGGAT & СССTTACACACACAGCCTGAAG & BT059884 \\
\hline Cathepsin S & GGCCACCATCGGACCTATCT & AGCAAGGACAGCATGGTTTGT & BT060402 \\
\hline Fatty acid-binding protein, liver & GCCAGGAGTTTTGGAGGTGAT & GGAGTTCCTCAGGGCCATCT & CA038193 \\
\hline
\end{tabular}

RPL 1, RNA polymerase 1

slope of the linear curve of cycle threshold values plotted against $\log$ dilution ${ }^{(45)}$. The stability of the reference genes was evaluated by geNorm ${ }^{(46)}$ and NormFinder ${ }^{(47)}$ as implemented in GenEx 4.3.5 (MultiD Analyses AB, Gothenburg, Sweden). Statistical testing was conducted with a pairwise random reallocation test in RESTC 2005 (Corbett Life Sciences, Mortlake, NSW, Australia) ${ }^{(48)}$, with cycle threshold values as the input variable and 5000 permutations. Results were considered significant when $P$ values were below $0 \cdot 05$. However, all $P$ values below $0 \cdot 15$ are given in the tables.

\section{Results}

\section{Maize ingredients and diets}

The only mycotoxin that differed between the two maize types was DON, with a level of $90 \mu \mathrm{g} / \mathrm{kg}$ in the GM maize, while the level in the non-GM maize was below the detection limit $(<2.5 \mu \mathrm{g} / \mathrm{kg}$; Table 3$)$. The levels of all other analysed mycotoxins were below their detection limits in both maize types. Several metabolites were present in different levels in the GM and non-GM maize (Table 4). The content of the sugar alcohols arabitol, sorbitol and mannitol was 3.4-, 3.7and $2 \cdot 9$-fold higher in the non-GM maize, while maltose was 2.9-fold higher. Of organic acids, benzoic acid was 2.4-fold higher, while gluconic acid, $\delta$-lactone and gluconic acid were 3.3- and 2.4-fold higher, respectively. p-Coumaric acid, (E)-cafferic acid, erythronic acid and galactonic acid were also higher in the non-GM maize: $2 \cdot 1-, 2 \cdot 4-, 2 \cdot 5-$ and $2 \cdot 4-$ fold, respectively. The most pronounced difference, however, was methyl linoleate, which was 78-fold higher in the non-GM maize. Total levels of sugars and fatty acids were similar in both maize types, while there was a $2 \cdot 1$-fold difference in the total level of organic acids, mainly due to higher levels of phosphoric and gluconic acid in the non-GM variety. Of the sixty-three measured metabolites, forty-eight compounds were confirmed based on Skogerson et al. ${ }^{(49)}$ (i.e. approximately $75 \%)$.

\section{Microarray results}

Some of the arrays hybridised with intestinal samples exhibited poor quality, based on log plots of red $v$. green channel intensity. Good-quality samples exhibited a relatively tight distribution cloud around the diagonal, while the poor-quality samples exhibited a poor relationship between the two channels. After removal of poor-quality samples with obvious technical defects, seven intestinal samples from the non-GM group and five intestinal samples from the GM group were retained for further analysis. For the liver samples, all nine arrays were of acceptable quality. After pre-processing and filtering, 7061 genes were used for analysis for the intestinal samples and 7239 genes for the liver samples.

Correspondence analysis is used for the visualisation of structures in the data, to look for the greatest covariances (between samples and genes), and can reveal clustering of the samples with the most similar overall gene expression profiles. For the intestinal samples, fish fed the diets containing GM and non-GM maize were clearly separated from each other, suggesting global differences between the two groups (Fig. 2). On which day the hybridisations had been performed also appeared to have some effect. All the samples from fish fed the diet containing GM maize clustered closely together

Table 3. Mycotoxins in the non-GM and GM maize varieties used in the feeds (in $\mu \mathrm{g} / \mathrm{kg}$ )

\begin{tabular}{lcc}
\hline & Non-GM maize & GM maize \\
\hline Mycotoxins & & \\
Aflatoxin $\mathrm{B}_{1}$ & $<2.5$ & $<2.5$ \\
Aflatoxin $\mathrm{B}_{2}$ & $<0.10$ & $<0.10$ \\
Aflatoxin $\mathrm{G}_{1}$ & $<0.20$ & $<0.20$ \\
Aflatoxin $\mathrm{G}_{2}$ & $<0.15$ & $<0.15$ \\
Deoxynivalenol & $<2.5$ & 90 \\
HT-2 toxin & $<2.5$ & $<2.5$ \\
Nivalenol & $<25$ & $<25$ \\
Ochratoxin $\mathrm{A}$ & $<0.015$ & $<0.015$ \\
T-2 toxin & $<2.5$ & $<2.5$ \\
Zearalenone & $<2.5$ & $<2.5$ \\
\hline
\end{tabular}


Table 4. Metabolites in the non-GM and GM maize varieties used in the feeds $(\mathrm{mg} / \mathrm{kg})$ (Mean values of three analytical parallels and standard deviations)

\begin{tabular}{|c|c|c|c|c|c|}
\hline & \multicolumn{2}{|c|}{ Non-GM maize } & \multicolumn{2}{|c|}{ GM maize } & \multirow[b]{2}{*}{ Fold difference } \\
\hline & Mean & SD & Mean & SD & \\
\hline \multicolumn{6}{|l|}{ Sugar and sugar alcohols } \\
\hline Glycerol & 2190.04 & $22 \cdot 57$ & $1656 \cdot 97^{\star}$ & 6.44 & $1 \cdot 3$ \\
\hline Erythritol & 22.7 & 0.44 & $11 \cdot 80^{\star}$ & 0.07 & 1.9 \\
\hline Xylose & $8 \cdot 78$ & 0.21 & 8.59 & 0.13 & $1 \cdot 0$ \\
\hline Ribose & $6 \cdot 11$ & 0.05 & $5 \cdot 35^{\star}$ & 0.03 & $1 \cdot 1$ \\
\hline Xylitol & $9 \cdot 14$ & 0.25 & $6 \cdot 86^{\star}$ & 0.04 & $1 \cdot 3$ \\
\hline Arabitol & $60 \cdot 16$ & 0.30 & $17 \cdot 78^{\star}$ & 0.78 & 3.4 \\
\hline n.i. (sugar) & 13.51 & 0.19 & $9 \cdot 18^{*}$ & 0.22 & 1.5 \\
\hline Fructose & 952.63 & $21 \cdot 38$ & $628 \cdot 36^{\star}$ & 28.29 & 1.5 \\
\hline Galactose & $11 \cdot 70$ & 0.11 & $22 \cdot 37^{\star}$ & 2.09 & 0.5 \\
\hline Mannose & 23.08 & 1.57 & $13 \cdot 65^{\star}$ & 0.25 & $1 \cdot 7$ \\
\hline Arabinofuranose & $6 \cdot 19$ & 0.38 & $5 \cdot 51^{\star}$ & 0.15 & $1 \cdot 1$ \\
\hline Arabinopyranose & 19.96 & 0.57 & $17 \cdot 91^{*}$ & 0.45 & $1 \cdot 1$ \\
\hline Glucose & 514.43 & 5.92 & $309 \cdot 55^{\star}$ & 1.04 & 1.7 \\
\hline Sorbitol & 13.05 & 0.42 & $3.53^{\star}$ & 0.19 & 3.7 \\
\hline Mannitol & $626 \cdot 38$ & $30 \cdot 58$ & $219 \cdot 15^{\star}$ & 1.98 & $2 \cdot 9$ \\
\hline Galactitol & $12 \cdot 62$ & 0.17 & $12 \cdot 74$ & 0.18 & 1.0 \\
\hline Myoinositol & 77.46 & 0.56 & $49 \cdot 60^{\star}$ & 0.83 & 1.6 \\
\hline Sucrose & $17325 \cdot 68$ & $1019 \cdot 02$ & $20229 \cdot 07^{*}$ & $376 \cdot 20$ & 0.9 \\
\hline Laminaribiose & 69.86 & 3.81 & $45 \cdot 64^{*}$ & 3.90 & 1.5 \\
\hline Cellobiose & $5208 \cdot 10$ & $138 \cdot 36$ & $3584 \cdot 48^{*}$ & $108 \cdot 30$ & 1.5 \\
\hline Maltose & 75.44 & 4.51 & $26 \cdot 12^{*}$ & 0.96 & 2.9 \\
\hline Trehalose & $85 \cdot 47$ & $6 \cdot 34$ & $66 \cdot 72^{*}$ & $5 \cdot 29$ & $1 \cdot 3$ \\
\hline Threitol & 3.57 & $0 \cdot 10$ & $3 \cdot 70$ & 0.11 & 1.0 \\
\hline Galactinol & $9 \cdot 01$ & 0.28 & $10 \cdot 23^{\star}$ & 0.47 & 0.9 \\
\hline n.i. (disaccharide) & $21 \cdot 00$ & $2 \cdot 33$ & $26 \cdot 00^{*}$ & 1.94 & 0.8 \\
\hline n.i. (polyol) & $11 \cdot 18$ & 0.29 & $12 \cdot 00$ & 1.03 & 0.9 \\
\hline Total & \multicolumn{2}{|c|}{27377} & \multicolumn{2}{|c|}{27003} & 1.0 \\
\hline \multicolumn{6}{|l|}{ Organic acids } \\
\hline Lactic acid & 12.96 & 0.47 & $13 \cdot 13$ & 0.05 & 1.0 \\
\hline Glycolic acid & $3 \cdot 18$ & 0.07 & $2 \cdot 42^{\star}$ & 0.05 & 1.3 \\
\hline Methyl 2-ethyl-malonic acid & $3 \cdot 11$ & 0.05 & $2 \cdot 76^{\star}$ & 0.01 & $1 \cdot 1$ \\
\hline Ethyl phosphate & 2.97 & 0.01 & $2 \cdot 32^{*}$ & 0.02 & $1 \cdot 3$ \\
\hline Benzoic acid & $1 \cdot 78$ & 0.12 & $0.73^{*}$ & 0.01 & $2 \cdot 4$ \\
\hline 4-Hydroxy butyric acid & $2 \cdot 19$ & 0.02 & $1.62^{*}$ & 0.07 & $1 \cdot 4$ \\
\hline Phosphoric acid & 339.95 & 1.23 & $155 \cdot 84^{*}$ & 5.83 & $2 \cdot 2$ \\
\hline Succinic acid & 2.63 & 0.12 & $1.94^{*}$ & 0.09 & 1.4 \\
\hline Glyceric acid & $3 \cdot 24$ & 0.06 & $2 \cdot 48^{*}$ & 0.13 & 1.4 \\
\hline Fumaric acid & 3.54 & 0.04 & $2 \cdot 28^{*}$ & 0.06 & 1.6 \\
\hline Malic acid & 4.44 & 0.04 & $5 \cdot 07^{\star}$ & 0.31 & 0.9 \\
\hline Threonic acid & $5 \cdot 21$ & 0.19 & $2 \cdot 62^{\star}$ & 0.13 & $2 \cdot 0$ \\
\hline Glycerol-3-phosphate & 21.08 & 0.40 & $18 \cdot 05^{\star}$ & 0.34 & 1.2 \\
\hline n.i. (organic acid) & $2 \cdot 40$ & 0.22 & $1 \cdot 22^{*}$ & 0.05 & $2 \cdot 0$ \\
\hline Citric acid & $4 \cdot 17$ & 0.21 & $2.98^{*}$ & 0.07 & 1.4 \\
\hline Gluconic acid, $\delta$-lactone & $22 \cdot 30$ & $2 \cdot 06$ & $6 \cdot 72^{*}$ & 0.13 & $3 \cdot 3$ \\
\hline Galactonic acid, $\gamma$-lactone & 32.97 & $1 \cdot 14$ & $13 \cdot 86^{\star}$ & 0.38 & $2 \cdot 4$ \\
\hline$p$-Coumaric acid & $59 \cdot 76$ & 3.30 & $28 \cdot 14^{\star}$ & $1 \cdot 17$ & $2 \cdot 1$ \\
\hline Gluconic acid & $132 \cdot 76$ & $8 \cdot 77$ & $54.92^{\star}$ & 0.36 & $2 \cdot 4$ \\
\hline Galactonic acid & 3.42 & 0.02 & $2 \cdot 46^{\star}$ & 0.08 & $1 \cdot 4$ \\
\hline$(E)$-Ferulic acid & 3.62 & 0.05 & $3 \cdot 26^{*}$ & 0.08 & $1 \cdot 1$ \\
\hline (E)-Caffeic acid & $18 \cdot 89$ & 0.31 & $7 \cdot 52^{\star}$ & 0.04 & 2.5 \\
\hline (E)-Sinapic acid & $10 \cdot 20$ & 0.73 & $9 \cdot 27^{\star}$ & 0.18 & $1 \cdot 1$ \\
\hline Ribonic acid & 3.98 & 0.22 & $2 \cdot 07^{\star}$ & 0.17 & 1.9 \\
\hline Erythronic acid & $3 \cdot 31$ & $0 \cdot 10$ & $1 \cdot 31^{*}$ & 0.23 & $2 \cdot 5$ \\
\hline Syringic acid & $5 \cdot 15$ & 0.23 & $2 \cdot 95^{\star}$ & 0.25 & $1 \cdot 7$ \\
\hline Arabinonic acid, $\gamma$-lactone & 3.54 & 0.04 & $3 \cdot 17^{\star}$ & 0.05 & $1 \cdot 1$ \\
\hline Total & \multicolumn{2}{|c|}{710} & \multicolumn{2}{|c|}{337} & $2 \cdot 1$ \\
\hline \multicolumn{6}{|l|}{ Fatty acids } \\
\hline Myristic acid & 3.39 & 0.05 & $3 \cdot 22^{*}$ & 0.04 & $1 \cdot 1$ \\
\hline Palmitic acid & $663 \cdot 12$ & $7 \cdot 87$ & $532 \cdot 20^{*}$ & $2 \cdot 52$ & $1 \cdot 3$ \\
\hline Methyl oleate & $2 \cdot 22$ & 0.07 & $3 \cdot 11^{*}$ & 0.17 & 0.7 \\
\hline Methyl linoleate & $447 \cdot 78$ & 34.43 & $5 \cdot 74^{*}$ & 0.58 & $78 \cdot 0$ \\
\hline Linoleic acid & $3821 \cdot 24$ & 13.69 & $3447 \cdot 99^{\star}$ & 8.86 & $1 \cdot 1$ \\
\hline Oleic acid & 1231.51 & $8 \cdot 78$ & $1091 \cdot 80^{*}$ & 3.64 & $1 \cdot 1$ \\
\hline Stearic acid & $80 \cdot 38$ & 2.43 & $98 \cdot 61^{\star}$ & 1.80 & 0.8 \\
\hline Total & \multicolumn{2}{|c|}{6250} & 51 & & $1 \cdot 2$ \\
\hline Others & & & & & \\
\hline Norvaline & $2 \cdot 48$ & $0 \cdot 10$ & $1 \cdot 76^{*}$ & 0.05 & 1.4 \\
\hline n.i. (aromatic compound) & 1.53 & 0.02 & $1 \cdot 15^{\star}$ & 0.02 & $1 \cdot 3$ \\
\hline
\end{tabular}

n.i., Not identified.

${ }^{*}$ Mean value was significantly different from that for the non-GM maize $(P<0.05)$. 
in the plot, suggesting little technical variation among these, while the non-GM samples scattered more widely in the plot, and the arrays hybridised on days 1 and 2 seemed to clearly separate from each other.

The output of SAM is a ranked list of the most differentially expressed genes between the two diet groups. A $t$-score is calculated for each gene, and the false discovery rate (FDR, $q$ value), which is the expected proportion of false positives on the list, is calculated by permutation and can be used to account for multiple testing. Of the 7061 genes in the distal intestine, 494 genes were identified as differentially regulated with a $q$ value of 0 . Of these, 125 genes were up-regulated in the group fed the diet with GM maize, with an average fold change of 1.7 , while 369 genes were down-regulated in this group, with an average fold change of $2 \cdot 4$. If the FDR cutoff value had been set at $5 \%$, the number of differentially regulated genes would be 2490. Rank product results showed a similar picture in terms of more genes being down-regulated and also many of the same genes towards the top of the list, but FDR values were somewhat higher than with SAM. With an FDR limit of 5\%, 404 genes appeared to be down-regulated in the group fed the diet with GM maize, while sixteen appeared to be up-regulated in this group with the rank product method. With GSEA, no significantly enhanced gene sets were identified in either diet group (no gene sets with an FDR below 20\%).

From the intestinal data, eight genes were followed up by qPCR based on the SAM/rank product results. These were retinoic acid receptor (retinoid $\mathrm{X}$ receptor $\gamma$ ), high-affinity $\mathrm{Cu}$ uptake protein 1 , Hb subunit $\alpha 4$, splicing factor arginine/ serine-rich 16, anti-apoptotic protein NR13, Cu chaperone

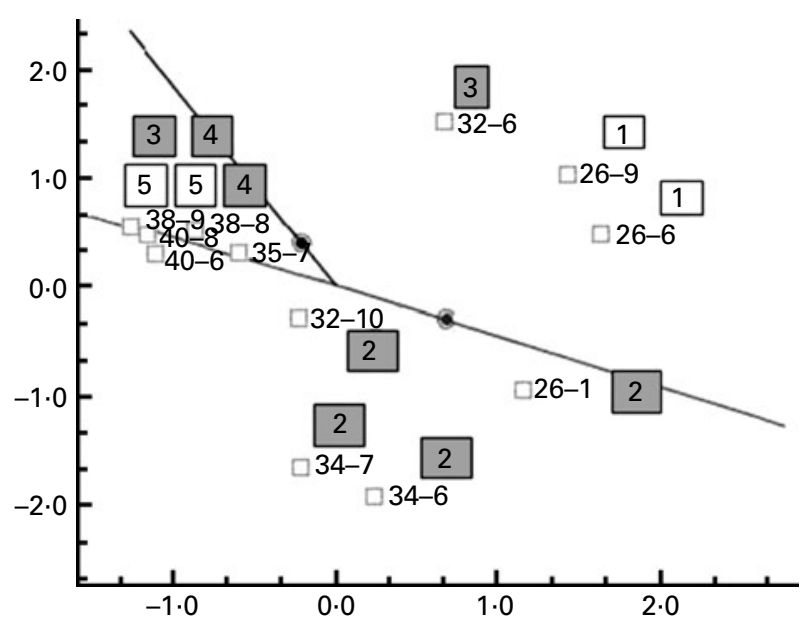

Fig. 2. Correspondence analysis plot of the pre-processed and normalised data (only including the samples that were used in the final data analysis, not the ones excluded due to poor quality). The numbers 26-1, 26-6, 26-9, $32-6,32-10,34-6$ and $34-7$ represent the individual samples from the non-GM-fed group, while the five remaining samples (clustering closely together in the figure) are from the GM-fed group. The numbers 1-5 in squares show the day on which the hybridisations were conducted (hybridisation days $1-5)$. As can be seen from the plot, samples from the two diet groups were not randomised across hybridisation days, and a day effect might be apparent in the data and would be difficult to distinguish from a diet effect. The samples from GM-fed fish cluster tightly together, while there seems to be much more variation (technical or biological) between the samples of non-GM-fed fish. for superoxide dismutase (SOD), ferritin heavy chain and tight junction protein ZO-2. Furthermore, another three genes (metallothionein (MT)-A, MT-B and cathepsin S precursor) were followed up based on the Excel ranking of intensities. Microarray and qPCR results for these genes are given in Tables 5 and 6 . One of the probes from the arrays that was followed up appears to have been incorrectly annotated as $\mathrm{Hb}$ subunit $\alpha$, BLAST search in the NCBI database matched this sequence to salmon $60 \mathrm{~S}$ ribosomal protein L14 with an $e$ value of $6 e^{-142}$ and a query coverage of $66 \%$, and no matches to $\mathrm{Hb}$ appeared in the list. As the primer pair used for qPCR was based on the (correctly annotated) $\mathrm{Hb}$ subunit $\alpha$ sequence from the liver data, this gene was excluded from further analysis. The annotations of all other sequences followed up by qPCR were checked and found to be correct. In cases where the full mRNA sequence for salmon was available in the GenBank, this was used as a basis for designing primers. However, for two of the genes, new primer pairs were also designed from the exact nucleotide sequence that appeared on the array, but this made no difference to the results (data not shown).

From the liver data, seven genes (claudin-3, gelsolin precursor, ferritin heavy subunit, MT-B, Hb subunit $\alpha$, fatty acidbinding protein and $\mathrm{Cu}$ chaperone for SOD) were followed up based on the Excel ranking of intensities. Microarray and qPCR results for these genes are given in Table 7.

\section{Quantitative $P C R$ results}

The non-amplification and non-template controls were negative for all genes. For the intestinal data, elongation factor $1 \alpha, \beta$-actin and HSP90 were used for normalisation based on expression stability and amplification efficiency, while HSP90 and RNA polymerase 1 were used to normalise the liver data.

Of the ten genes that were tested in the distal intestine, only one was identified as significantly different between the diet groups: anti-apoptotic protein NR13. The fold difference of $2 \cdot 28$ obtained by qPCR for this gene corresponds well with the $2 \cdot 30$-fold regulation observed in the microarray data. Overall, significant correlation $(r 0.85, P<0.05$, $\mathrm{Hb}$ was excluded) was observed between the fold changes observed in the microarray and the qPCR data. There was a tendency towards the up-regulation of both MT-A and MT-B $(P=0 \cdot 12$ and 0.06 , respectively), and also ferritin heavy subunit $(P=0 \cdot 12)$. However, for the two genes that appeared downregulated in the GM group from the microarray data, no similar trend could be observed in the qPCR data. Correlation between qPCR fold changes and intensities from the Excel analysis was also significant $(r 0.65, P<0.05)$. The qPCR data were also analysed, including only the exact same individual samples that were used in the microarray dataset; however, results regarding fold changes were very similar to the data that are presented, but none of the genes had $P$ values below $0 \cdot 15$, due to a smaller sample size than for the full dataset (results not shown).

In the liver, gelsolin precursor was significantly up-regulated with a fold difference of $2 \cdot 0(P=0.03)$, while ferritin heavy 
Table 5. Selected genes from the intestine, which were selected for the follow-up with quantitative PCR (qPCR) based on significance analysis of microarrays (SAM)/rank product results ${ }^{\star}$

\begin{tabular}{|c|c|c|c|c|c|c|}
\hline $\begin{array}{l}\text { GenBank } \\
\text { accession }\end{array}$ & Gene & $\begin{array}{l}\text { Rank, } \\
\text { SAM list }\end{array}$ & $\begin{array}{l}\text { FDR, } \\
\text { SAM }\end{array}$ & $\begin{array}{c}\text { FDR, } \\
\text { rank product }\end{array}$ & $\begin{array}{l}\text { Microarray } \\
\text { fold change }\end{array}$ & $\begin{array}{c}\text { qPCR } \\
\text { fold change }\end{array}$ \\
\hline CB514936 & Retinoic acid receptor (retinoid $X$ receptor $\gamma$ ) & 1 & 0.0 & 0.06 & 1.93 & 1.58 \\
\hline CA046761 & $\mathrm{Hb}$ subunit $\alpha 4 \dagger$ & 3 & 0.0 & 0.0 & $-4 \cdot 18$ & $-1 \cdot 19$ \\
\hline CA051050 & High-affinity Cu uptake protein 1 & 4 & 0.0 & 0.003 & -3.71 & $-1 \cdot 15$ \\
\hline CA051059 & Splicing factor, arginine/serine-rich 16 & 9 & 0.0 & 0.042 & $-2 \cdot 17$ & 1.14 \\
\hline CB517746 & Anti-apoptotic protein NR13 & 54 & 0.0 & 0.009 & $2 \cdot 31$ & $2 \cdot 28 \ddagger$ \\
\hline CB511929 & Cu chaperone for SOD & 226 & 0.0 & 0.024 & 2.00 & 2.00 \\
\hline CB511875 & Tight junction protein ZO-2 & 289 & 0.0 & 0.024 & 2.01 & 1.64 \\
\hline CB498077 & Ferritin heavy subunit & 2011 & 0.298 & 0.202 & 1.60 & $1.90 \S$ \\
\hline
\end{tabular}

FDR, false discovery rate; SOD, superoxide dismutase.

* The rank from the SAM list and the FDR values from both the SAM and the rank product analyses are given, in addition to microarray and qPCR fold changes. $P$ values from the qPCR data are given if below 0.15. Positive values for fold change means that the gene is up-regulated in the GM-fed group compared with the non-GM-fed group, whereas negative values means a down-regulation in the GM-fed group.

† This sequence appears to have been incorrectly annotated as Hb, BLAST search in the NCBI database matched this sequence to salmon $60 S$ ribosomal protein L14 with an $e$ value of $6 e^{-142}$ and a query coverage of $66 \%$, and no matches to $\mathrm{Hb}$ appeared in the list.

$\ddagger P=0.04$.

$\S N S, P=0 \cdot 12$.

subunit was significantly down-regulated $(P=0.02)$ with a fold difference of $-2 \cdot 39$. There was also a tendency towards the down-regulation of MT-B (fold change: $-2 \cdot 28, P=0.07$ ). Since only the group fed the diet with GM maize was hybridised, no fold change values were available from the microarray data for comparison, but there was a relatively good agreement between the directional change in the qPCR data and the average intensities from the microarray data, and these values were significantly correlated $(r 0 \cdot 66, P<0.05)$.

\section{Discussion}

The present study is part of a larger feeding study in which nutritional, physiological, stress and immune responses were evaluated and published elsewhere ${ }^{(16,17,26)}$. The analyses reported in the present study were conducted on preserved samples from this trial, to further elaborate the differences observed. The main findings reported in the previous studies were that fish fed the diet containing GM maize had significantly lower feed intake, resulting in reduced growth, but with no differences in feed conversion or digestibility. The relative sizes of the liver and the distal intestine were higher for fish fed the diet containing GM maize, and maltase activity in mid- and distal intestine and Na-dependent D-glucose uptake were also significantly higher. Evaluating stress and immune response-related biomarkers, higher levels of granulocytes and of granulocytes plus monocytes relative to lymphocytes in the blood, higher total SOD enzyme activity both in the liver and distal intestine, lower catalase activity in the liver and an increased protein level of HSP70 in the liver have been reported ${ }^{(17)}$. The design also included a reference diet containing suprex maize, with a similar macronutrient composition as the experimental diets. Regarding some parameters, the reference group was intermediate between the GM and non-GM groups (i.e. growth and liver index) and not significantly different from either, indicating that fish in both diet groups were within the normal range for healthy salmon. However, the present experiment was carried out to shed some light on these observed differences by identifying possible differences between the two maize ingredients that might be responsible, and using microarray to screen for the effects on the fish as the previous study has shown significant effects on several physiological parameters, but has been unable to elucidate the cause/mechanism of these effects.

Microarray is often considered a tool for the generation of hypotheses, rather than a method for providing all the answers. We chose to allow $40 \%$ missing values due to the high level of noise present in the data, in order not to lose valuable information. This, in addition to the suspicion of potential day or batch effects, made it crucial to verify the microarray results for the intestine by qPCR. The liver microarray data could not be used to draw inferences but simply

Table 6. Selected genes from the intestine followed up by quantitative PCR (qPCR), based on the ranked list of average intensities of GM samples co-hybridised with the non-GM reference pool

(hybridisations of the non-GM samples not included in the analysis)*

\begin{tabular}{llcccc}
\hline GenBank accession no. & Gene & Average intensity & CV (\%) & Consistency $\dagger$ & qPCR fold change \\
\hline CB492197 & Metallothionein A & 1.09 & $50 \cdot 2$ & $5: 5$ & $1.54 \ddagger$ \\
CK990241 & Cathepsin S precursor & 1.02 & 26.1 & $5: 5$ & 1.09 \\
CK990996 & Metallothionein B & 0.94 & 79.5 & $4: 5$ & $1.69 \S$ \\
\hline
\end{tabular}

* The three selected genes were ranked numbers 1,4 and 11 in the list of highest intensity values. $P$ values from the qPCR data are given if below $0 \cdot 15$.

† Ratio of samples apparently regulated in the same direction.

$\ddagger$ NS, $P=0 \cdot 12$.

$\S$ NS, $P=0.06$. 
Table 7. Selected genes from the liver followed up by quantitative PCR (qPCR) based on the ranked list of average intensities from the nine GM samples co-hybridised with the pooled reference sample of the non-GM-fed fish*

\begin{tabular}{llcccc}
\hline GenBank accession no. & Gene & Average intensity & CV (\%) & Consistency $\dagger$ & qPCR fold change \\
\hline CA060997 & Claudin-3 & 0.45 & 96.5 & $8: 9$ & -1.45 \\
CA060998 & Gelsolin precursor & 0.44 & 62.6 & $9: 9$ & $2.00 \ddagger$ \\
CB489257 & Ferritin, heavy subunit & -0.75 & 59.4 & $9: 9$ & $-2.39 \S$ \\
CA039745 & Hb subunit $\alpha$ & -0.65 & $92 \cdot 2$ & $8: 9$ & -1.75 \\
CB507722 & Metallothionein B & -0.63 & 39.6 & $9: 9$ & $-2.28 \|$ \\
CA038193 & Fatty acid-binding protein & -0.44 & 87.6 & $9: 9$ & -1.38 \\
CB511929 & Cu chaperone for SOD & 0.31 & 96.0 & $7: 9$ & -1.40 \\
\hline
\end{tabular}

SOD, superoxide dismutase.

* $P$ values from the qPCR data are given if below 0.15 .

† Ratio of samples apparently regulated in the same direction.

$\ddagger P=0.033$.

$\S P=0.019$

\| NS, $P=0.07$.

to generate hypotheses for further testing; as the group fed the diet with non-GM maize was only represented by one pooled sample and statistical testing was not possible. Furthermore, the pooled non-GM sample was consistently labelled with Cy5, while the GM samples were labelled with Cy3, which would confound diet effects with dye bias ${ }^{(50-52)}$. Dye bias could explain the better correlation obtained for the intestinal data between qPCR and microarray fold differences ( $r$ 0.85) compared with the correlation between qPCR and intensity values of only the GM-fed group hybridised against the reference $(r 0.65)$. From this, it appears that day or batch effects, if present, are at least less prominent than the dye bias and may not present a problem.

However, some discrepancies between the microarray and qPCR results are not readily explained. Especially, the downregulated genes in the microarray were not verified by qPCR. There were more regulated genes and larger fold changes in this direction, which might indicate a systematic bias. The positively regulated genes, on the other hand, were generally supported by the qPCR data regarding the direction and magnitude of the change, although the qPCR results were non-significant for most genes, and the statistical confidence in the microarray analysis appears overestimated. Rank product might be more realistic than SAM in terms of FDR values, but this analysis also revealed many downregulated genes (including the two that were not verified by qPCR). The FDR is the ratio of false positives to rejected hypotheses (ratio of features expected to be false discoveries) ${ }^{(53)}$. It is surprising that this value is zero in the SAM analysis for a long list of genes, despite modest fold differences. Due to large variations in gene expression data, twofold or greater differences are often required to achieve statistical significance, although this will also depend on the level of replication. However, many, if not most, biological processes involve less than twofold changes ${ }^{(54)}$. Modest fold changes have often been reported in nutrigenomic studies ${ }^{(55,56)}$.

In order to better understand the long list of differentially regulated genes, GSEA could be a useful approach ${ }^{(40)}$. Despite the large number of apparently up- or down-regulated individual genes, no gene sets were significant. This could support the theory that the genes that came up in the SAM list as differentially regulated are caused by artefacts and do not represent true biological effects, in which case one would expect to see some pattern with certain pathways (gene sets) being affected. However, this could also reflect on the poor annotation of the salmon genome; unknown sequences on the array will not be included in gene sets, which can reduce the usefulness of GSEA. Approximately 25\% of the genes on the cGRASP array are uncharacterised, and about one-third of the known sequences lack a functional annotation.

qPCR is the most frequently used method for reliable quantification of gene expression ${ }^{(57)}$ and is generally considered to be more accurate than microarray. Up-regulation of anti-apoptotic protein and also a tendency towards the up-regulation of both MT-A, MT-B and ferritin heavy subunit in the distal intestine detected by qPCR indicate that there is a differential effect of the two feeds on the fish. In salmonids, there are two MT isoforms, MT-A and MT-B, which seem to possess slightly different roles, although these are not fully explored $^{(58)}$. MT are assumed to have roles related to the regulation of physiological metals, detoxification of xenobiotic metals and scavenging of free radicals and reactive oxygen metabolites, although the mechanisms are not completely understood $^{(59-62)}$. MT are often used as indicators for heavy metal exposure in fish and also of cellular stress, as they are induced by acute physical stress as well as by glucocorticoid hormones ${ }^{(63,64)}$. There is no in vivo evidence of antioxidant properties of MT in fish, but this has been indicated by in vitro studies ${ }^{(58)}$. Physiological metals, such as $\mathrm{Cu}, \mathrm{Zn}$ and Fe, with redox properties, and thus also MT, have roles in apoptosis, which can be induced by oxidative damage ${ }^{(65)}$. A difference in mRNA expression of MT could suggest differences in mineral/heavy metal content between the diets; however, mineral mix was added in equal amount to both diets, and the selection of analysed minerals exhibited minor differences between the diets (Table 1, footnote).

There were also indications of changes in antioxidant status in the liver, with the up-regulation of gelsolin precursor, down-regulation of ferritin heavy chain and a tendency towards the down-regulation of MT-B. Gelsolin is an actinbinding protein and a key regulator of actin filament assembly and disassembly, which is important in cell motility. It may possibly also inhibit apoptosis by stabilising mitochondria, 
although this role is somewhat controversial and may be involved in gene regulation ${ }^{(66)}$. Ferritin is a key molecule in limiting pro-oxidant stress and plays an important role in $\mathrm{Fe}$ homeostasis. Expression of ferritin heavy subunit in mammals is induced by cytokines and inflammation, and also by hormones, growth factors and second messengers ${ }^{(67)}$. Furthermore, it is up-regulated by oxidative stress. Both transcriptional and post-transcriptional mechanisms for this induction have been suggested ${ }^{(67)}$, which might limit the changes observed on an mRNA level as in the present study. It is interesting to note that both MT-B and ferritin heavy subunit exhibit opposite trends in the liver and distal intestine.

The results from both the liver and distal intestine strengthen the indications of differences in cellular stress response/oxidative stress between fish fed diets containing GM and non-GM maize. In a previous work on the same fish as used in the present study, changes were detected in the enzyme activity/protein levels of SOD, catalase and HSP70, but changes were not detected in transcription of the corresponding genes ${ }^{(16)}$, thus these effects would not have been detected in a microarray study. Low correlation is often observed between mRNA and protein; protein levels are determined by degradation and secretion, as well as by transcription, and there are post-translational modifications and time discrepancies between mRNA and protein expression $^{(68-70)}$. Another issue is how to interpret changes detected in gene expression. If there is an up-regulation of antioxidant defences, this does not necessarily mean that the fish are stressed; they may still be able to maintain homeostasis. However, this may require additional energy, thus affecting growth, and may also render the fish more vulnerable to infectious diseases or other secondary stressors.

Inconsistent and confusing results have been obtained when three feeding trials with diets containing GM maize in fish feed were carried out. The main conclusion in the three trials ranges from no difference ${ }^{(71)}$, reduced growth and stress response in salmon fed GM maize diets ${ }^{(16,17)}$ (the trial from which samples were obtained for the present study), and reduced growth and stress response in zebrafish fed non-GM maize diets ${ }^{(29)}$. A possible explanation could be varying levels of mycotoxins, which have been used to explain higher weight gain in the GM-fed group in studies with broilers, broiler chicks and piglets ${ }^{(72)}$, although cause-effect relationships were not established. It is not known whether the level of $90 \mu \mathrm{g} / \mathrm{kg}$ of DON in the maize, which would constitute $27 \mu \mathrm{g} / \mathrm{kg}$ in the feed, has any negative effect on fish, but salmon is known to be particularly sensitive to harmful plant components. In rainbow trout (Salmo gairdneri), DON concentrations from $1000 \mu \mathrm{g} / \mathrm{kg}$ caused growth depression ${ }^{(73)}$, but lower concentrations were unfortunately not tested. The European Food Safety Authority has set the tolerable daily intake for humans at $1 \mu \mathrm{g} / \mathrm{kg}$ body weight per $\mathrm{d}^{(28)}$.

Regarding the stress and antioxidant responses reported previously in the fish used for the present study ${ }^{(17)}$, various mycotoxins have been shown to increase HSP70 expression in rat brain, the placenta of pregnant rats, rat fetal livers and cell cultures $^{(74-76)}$, and to increase SOD-1 in rat brain ${ }^{(74)}$, but decrease it in the liver of pregnant rats ${ }^{(75)}$. DON induces lipid peroxidation in human intestinal cells ${ }^{(77)}$, which could explain the indications of oxidative stress in our fish. In rat liver culture, there was a concentration-dependent increase in oxidative stress caused by DON, increased lipid peroxidation and decreased SOD, while antioxidant supplementation protected against toxicity ${ }^{(78)}$. In a hepatic cell line, DON exposure seemed to cause the generation of reactive oxygen species, and increased catalase and SOD activities ${ }^{(79)}$. Furthermore, feedstuffs naturally contaminated with the mycotoxins DON and zearalenone decreased the number of lymphocytes and total leucocytes in hens ${ }^{(80)}$, which also seems to fit with results reported from fish in the present study ${ }^{(17)}$. Apoptosis has been suggested as one of the main mechanisms of DON toxicity in intestinal cells ${ }^{(81)}$, which fits with the upregulation of anti-apoptotic protein in the intestine of our salmon fed the GM maize diet. Our observed down-regulation of MT-B in the liver is consistent with reports on rats fed mouldy wheat containing DON in addition to other mycotoxins ${ }^{(82)}$. However, treatment with DON slightly decreased D-glucose uptake in mice ${ }^{(83)}$, and in human epithelial cells, the Na-dependent D-GLUT were strongly inhibited by $\mathrm{DON}^{(81)}$. This is contrary to the results reported in our salmon $^{(17)}$, where the intestine from fish fed the diet containing GM maize exhibited increased glucose uptake.

Large variability in mycotoxins is observed between locations and growing seasons both in GM and non-GM maize, but the general trend is reduced levels in $B t$-maize compared with conventional maize varieties, due to better resistance against Fusarium spp. when there is limited insect damage to the plant ${ }^{(84-87)}$. When data on the relationship between mycotoxins (fumonisins, DON and zearalenone) and $B t$-maize were reviewed, nineteen out of twenty-three studies have shown that mycotoxin concentrations were higher in non-GM varieties, but regarding DON specifically, the relationship was less clear with five against three studies $^{(88)}$.

Differences were observed in metabolite profiles between the two maize varieties, but this is to be expected in crops grown in separate fields; growing season and location are generally more prominent factors causing variation than genetic background $^{(49,89-91)}$. This was also the case for protein expression when GM maize was compared with its nearisogenic line, but differences due to the particle bombardment were also detected ${ }^{(92)}$. Reasons for the particularly large fold difference in methyl linoleate are not clear, but linoleic acidderived hydroperoxides are supposed to be modulators of mycotoxin biosynthesis in plants ${ }^{(93)}$. Interestingly, $p$-coumaric acid, benzoic acid and $(E)$-cafferic acids were also higher in the non-GM maize. $p$-Coumaric, benzoic and caffeic acids have been shown to be elevated in wheat strains with a high degree of resistance to Fusarium infection ${ }^{(94)}$. The nonGM maize also had higher levels of mannitol, which is increased in response to salt and osmotic stress, but possibly also has a role in response to pathogen attack ${ }^{(95)}$. Gluconic acid, a mild organic acid derived from glucose, was also higher in the non-GM maize. Gluconic acid is abundantly present in plants but is also produced by various micro-organisms and fungi; the mycotoxin-producing fungus Aspergillus niger 
is commonly used in industrial production ${ }^{(96)}$. It has also been shown that gluconic acid can function as an anti-fungal compound in plants ${ }^{(97)}$. Potentially, one or several of the metabolites exhibiting different levels in the GM and non-GM maize could be related to effects observed in the fish. However, lack of relevant literature regarding effects of these metabolites on production animals, including fish, makes it difficult to speculate. As maize is a commonly used feed ingredient, one might expect that if any of these metabolites had equally negative effects on the health, feed intake and growth of production animals as mycotoxins, such literature would have existed. Cry proteins represent another difference between GM and non-GM maize ingredients. However, salmon diets are extruded (heat-treated under pressure), which would be expected to denature ${ }^{(98)}$, as has also been found for zebrafish diets receiving less heat treatment than commercial salmon diets ${ }^{(29)}$. Consequently, we consider DON a more likely cause of the observed effects than any of the other differences in metabolites, although the evidence for DON as a causative factor is circumstantial and requires direct testing.

The use of near-isogenic lines in the evaluation of GM plants, despite being the recommended control ${ }^{(99,100)}$, is not perfect in this regard, as shown by both the mycotoxin and metabolite analyses of our two maize types. When numerous differences are present between the GM and non-GM varieties, some of which might be due to unintended effects of the genetic modification, while others are random differences that would vary between locations and seasons even in genetically identical cultivars, it becomes challenging to elucidate the cause of observed differences in animals fed these plants. Regarding fish, more knowledge is required on the effect of low mycotoxin doses in order to distinguish these from potential 'GM effects'. The present microarray data support and strengthen indications of changes in cellular stress/ antioxidant status observed previously in the liver and distal intestine of these fish. However, it cannot be concluded whether the observed effects can be attributed to the analysed difference in DON or to another aspect of the GM maize ingredient.

\section{Acknowledgements}

We are grateful to Matthew Rise at the University of Victoria, Canada, and Susan Douglas at the Institute for Marine Biosciences (NRC IMB), Canada, for helping with the microarray design. We thank Jacob Wessels for great technical assistance before, during and after the feeding trial and Betty Irgens for technical assistance at the molecular laboratory. The authors wish to acknowledge the support of the Norwegian Research Council (grants no. 142474 and 172151) and of the OECD's Co-operative Research Program: Biological Resource Management for Sustainable Agriculture Systems in the funding of the present study. The maize ingredients used in the present study were obtained from the Monsanto Company, but no economical funding or further support was received from this company. Consequently, the authors state that there are no conflicts of interest regarding the present study.
The contributions of the authors were as follows: M. S., G.-I. H. and A. S. participated in the planning of the feeding trial and diets, A. S. isolated and tested the quality of RNA, and M. S., together with S. P. L. and J. W., planned and conducted the microarray laboratory work in Canada. K. P. was responsible for the pre-processing and quality control of the microarray data at CBU. J. R. conducted the analysis and verification of metabolites in the maize samples. N. H. S., in collaboration with M. S., analysed the microarray data, performed the qPCR laboratory work and analysis, and was the main author. All authors have given inputs in the writing process and proofread the manuscript.

\section{References}

1. Anonymous (2009) Gennytt 5. http://www.oikos.no/newsread/ news.asp?docid $=11097$

2. Kaushik SJ \& Hemre G-I (2008) Plant proteins as alternative sources for fish feed and farmed fish quality. In Improving Farmed Fish Quality and Safety, pp. 300-327 [Ø Lie, editor]. Cambridge: Woodhead Publishing Limited/CRC Press.

3. James C (2009) Global status of commercialized biotech/ GM crops: 2009. In ISAAA Brief, No. 41. Ithaca, NY: ISAAA.

4. Somers DA \& Makarevitch I (2004) Transgene integration in plants: poking or patching holes in promiscuous genomes? Curr Opin Biotechnol 15, 126-131.

5. Fladung M (1999) Gene stability in transgenic aspen (Populus). I. Flanking DNA sequences and T-DNA structure. Mol Gen Genet 260, 574-581.

6. Kumar RS, Ijiri S, Kight K, et al. (2000) Cloning and functional expression of a thyrotropin receptor from the gonads of a vertebrate (bony fish): potential thyroidindependent role for thyrotropin in reproduction. Mol Cell Endocrinol 167, 1-9.

7. Kumar S \& Fladung M (2000) Transgene repeats in aspen: molecular characterisation suggests simultaneous integration of independent T-DNAs into receptive hotspots in the host genome. Mol Gen Genet 264, 20-28.

8. Cellini F, Chesson A, Colquhoun I, et al. (2004) Unintended effects and their detection in genetically modified crops. Food Chem Toxicol 42, 1089-1125.

9. Kuiper HA, Kleter GA, Noteborn HPJM, et al. (2001) Assessment of the food safety issues related to genetically modified foods. Plant J 27, 503-528.

10. Prescott VE, Campbell PM, Moore A, et al. (2005) Transgenic expression of bean $\alpha$-amylase inhibitor in peas results in altered structure and immunogenicity. J Agric Food Chem 53, 9023-9030.

11. Knowles BH (1994) Mechanism of action of Bacillus thuringiensis insecticidal $\delta$-endotoxins. Adv Insect Phys 24, $275-308$.

12. VKM (2009) Helse- og miljørisikovurdering genmodifisert maishybrid Bt11 × MIR162 $\times$ GA21 fra Syngenta Crop Protection AG (EFSA/GMO/DE/2009/67) (Health and environmental risk assessment of genetically modified maize Bt11 hybrid $\times$ MIR162 $\times$ GA21 from Syngenta Crop Protection AG (EFSA/ GMO/DE/2009/67)). Norwegian Scientific Committee for Food Safety. http://vkm.no/dav/af6b4973b1.pdf.

13. Vázquez-Padrón RI, Moreno-Fierros L, Neri-Bazán L, et al. (1999) Intragastric and intraperitoneal administration of Cry1Ac protoxin from Bacillus thuringiensis induces systemic and mucosal antibody responses in mice. Life $S c i$ 64, 1897-1912. 
14. Vázquez-Padrón RI, Gonzáles-Cabrera J, García-Tovar C, et al. (2000) Cry1Ac protoxin from Bacillus thuringiensis sp. kurstaki HD73 binds to surface proteins in the mouse small intestine. Biochem Biophys Res Commun 271, 54-58.

15. Moreno-Fierros L, García N, Gutiérrez R, et al. (2000) Intranasal, rectal and intraperitoneal immunization with protoxin Cry1Ac from Bacillus thuringiensis induces compartmentalized serum, intestinal, vaginal and pulmonary immune responses in Balb/c mice. Microbes Infect 2, 885-890.

16. Sagstad A, Sanden M, Haugland $\varnothing$, et al. (2007) Evaluation of stress- and immune-response biomarkers in Atlantic salmon, Salmo salar L., fed different levels of genetically modified maize (Bt maize), compared with its near-isogenic parental line and a commercial suprex maize. J Fish Dis $\mathbf{3 0}$, 201-212.

17. Hemre GI, Sagstad A, Bakke-McKellep AM, et al. (2007) Nutritional, physiological, and histological responses in Atlantic salmon, Salmo salar L. fed diets with genetically modified maize. Aquacult Nutr 13, 186-199.

18. Hammond BG, Dudek R, Lemen JK, et al. (2006) Results of a 90-day safety assurance study with rats fed grain from corn borer-protected corn. Food Chem Toxicol 44, 1092-1099

19. Séralini G-E, Cellier D \& de Vendomois J (2007) New analysis of a rat feeding study with a genetically modified maize reveals signs of hepatorenal toxicity. Arch Environ Contam Toxicol 52, 596-602.

20. EFSA (2007) EFSA review of statistical analyses conducted for the assessment of the MON 863 90-day rat feeding study. http://www.efsa.europa.eu/fr/scdocs/doc/19r.pdf

21. Doull J, Gaylor D, Greim HA, et al. (2007) Report of an Expert Panel on the reanalysis by of a 90-day study conducted by Monsanto in support of the safety of a genetically modified corn variety (MON 863). Food Chem Toxicol 45 , 2073-2085.

22. Kiliç A \& Akay MT (2008) A three generation study with genetically modified Bt corn in rats: biochemical and histopathological investigation. Food Chem Toxicol 46, $1164-1170$.

23. Kuiper HA, Kok EJ \& Engel KH (2003) Exploitation of molecular profiling techniques for GM food safety assessment Curr Opin Biotechnol 14, 238-243.

24. Sissener NH, Martin SAM, Cash P, et al. (2010) Proteomic profiling of liver from Atlantic salmon (Salmo salar) fed genetically modified soy compared to the near-isogenic non-GM line. Mar Biotechnol 12, 273-281.

25. Frøystad MK, Lilleeng E, Bakke-McKellep AM, et al. (2008) Gene expression in distal intestine of Atlantic salmon (Salmo salar L.) fed genetically modified soybean meal. Aquacult Nutr 14, 204-214.

26. Frøystad-Saugen MK, Lilleeng E, Bakke-McKellep AM, et al. (2008) Distal intestinal gene expression in Atlantic salmon (Salmo salar L.) fed genetically modified maize. Aquacult Nutr 15, 104-115.

27. von Schalburg K, Rise M, Cooper G, et al. (2005) Fish and chips: various methodologies demonstrate utility of a 16,006-gene salmonid microarray. BMC Genomics 6, 126.

28. EFSA (2004) Opinion of the Scientific Panel on Contaminants in the Food Chain on a request from the Commission to Deoxynivalenol (DON) as an undesirable substance in animal feed. EFSA J 73, 1-41.

29. Sissener NH, Johannessen LE, Hevrøy EM, et al. (2010) Zebrafish (Danio rerio) as a model for investigating the safety of genetically modified feed ingredients (soya and maize); performance, stress response and uptake of dietary DNA sequences. Br J Nutr 103, 3-15.

30. NRC (1993) Nutrient Requirement of Fish. Washington, DC: National Research Council/National Academy Press.

31. Baeverfjord G \& Krogdahl ^ (1996) Development and regression of soybean meal induced enteritis in Atlantic salmon, Salmo salar L., distal intestine: a comparison with the intestines of fasted fish. J Fish Dis 19, 375-387.

32. Krogdahl A \& Bakke-McKellep AM (2005) Fasting and refeeding cause rapid changes in intestinal tissue mass and digestive enzyme capacities of Atlantic salmon (Salmo salar L.). Comp Biochem Physiol A: Mol Integr Physiol 141, 450-460.

33. Brazma A, Hingamp P, Quackenbush J, et al. (2001) Minimum information about a microarray experiment (MIAME)-toward standards for microarray data. Nat Genet 29, 365-371.

34. Dysvik B \& Jonassen I (2001) J-Express: exploring gene expression data using Java. Bioinformatics 17, 369-370

35. Cleveland WS \& Devlin SJ (1988) Locally weighted regression: an approach to regression analysis by local fitting. J Am Stat Assoc 83, 596-610.

36. Bo TH, Dysvik J \& Jonassen I (2004) LSimpute: accurate estimation of missing values in microarray data with least squares methods. Nucleic Acids Res 32, e34.

37. Yang YH, Dudoit S, Luu P, et al. (2002) Normalization for cDNA microarray data: a robust composite method addressing single and multiple slide systematic variation. Nucleic Acids Res 30, e15.

38. Fellenberg K, Hauser NC, Brors B, et al. (2001) Correspondence analysis applied to microarray data. Proc Natl Acad Sci U S A 98, 10781-10786.

39. Tusher V, Tibshirani R \& Chu C (2001) Significance analysis of microarrays applied to transcriptional responses to ionizing radiation. Proc Natl Acad Sci U S A 98, 5116-5121.

40. Subramanian A, Tamayo P, Mootha VK, et al. (2005) Gene set enrichment analysis: a knowledge-based approach for interpreting genome-wide expression profiles. Proc Natl Acad Sci U S A 102, 15545-15550.

41. Moore LJ, Somamoto T, Lie KK, et al. (2005) Characterisation of salmon and trout $\mathrm{CD} 8 \alpha$ and $\mathrm{CD} 8 \beta$. Mol Immunol 42, 1225-1234.

42. Olsvik P, Lie K, Jordal A-E, et al. (2005) Evaluation of potential reference genes in real-time RT-PCR studies of Atlantic salmon. BMC Mol Biol 6, 21.

43. Hevrøy EM, El-Mowafi A, Taylor RG, et al. (2007) Lysine intake affects gene expression of anabolic hormones in atlantic salmon, Salmo salar. Gen Comp Endocrinol 152, $39-46$.

44. Jørgensen S, Kleveland E, Grimholt U, et al. (2006) Validation of reference genes for real-time polymerase chain reaction studies in Atlantic salmon. Mar Biotechnol 8, $398-408$

45. Higuchi R, Fockler C, Dollinger G, et al. (1993) Kinetic PCR analysis: real-time monitoring of DNA amplification reactions. Biotechnology (N Y) 11, 1026-1030.

46. Vandesompele J, De Preter K, Pattyn F, et al. (2002) Accurate normalization of real-time quantitative RT-PCR data by geometric averaging of multiple internal control genes. Genome Biol 3, 0034.1-0034.11.

47. Andersen CL, Jensen JL \& Orntoft TF (2004) Normalization of real-time quantitative reverse transcription-PCR data: a model-based variance estimation approach to identify genes suited for normalization, applied to bladder and colon cancer data sets. Cancer Res 64, 5245-5250. 
48. Pfaffl MW, Horgan GW \& Dempfle L (2002) Relative expression software tool (REST) for group-wise comparison and statistical analysis of relative expression results in realtime PCR. Nucleic Acids Res 30, e36.

49. Skogerson K, Harrigan GG, Reynolds TL, et al. (2010) Impact of genetics and environment on the metabolite composition of maize grain. J Agric Food Chem 58, 3600-3610.

50. Tseng GC, Oh MK, Rohlin L, et al. (2001) Issues in cDNA microarray analysis: quality filtering, channel normalization, models of variations and assessment of gene effects. Nucleic Acids Res 29, 2549-2557.

51. Dobbin KK, Kawasaki ES, Petersen DW, et al. (2005) Characterizing dye bias in microarray experiments. Bioinformatics 21, 2430-2437.

52. Smyth GK, Yang YH \& Speed T (2003) Statistical issues in cDNA microarray data analysis. In Functional Genomics: Methods and Protocols, vol. 224, pp. 111-136 [MJ Brownstein and $\mathrm{AB}$ Khodursky, editors]. Totowa, NJ: Humana Press, Inc.

53. Benjamini $Y$ \& Hochberg $Y$ (1995) Controlling the false discovery rate: a practical approach to multiple testing. J R Stat Soc B 57, 289-300.

54. Bild A \& Febbo PG (2005) Application of a priori established gene sets to discover biologically important differential expression in microarray data. Proc Natl Acad Sci US A 102, 15278-15279.

55. Jordal A-EO, Torstensen BE, Tsoi S, et al. (2005) Dietary rapeseed oil affects the expression of genes involved in hepatic lipid metabolism in Atlantic salmon (Salmo salar L.). J Nutr 135, 2355-2361.

56. Garosi P, De Filippo C, van Erk M, et al. (2005) Defining best practice for microarray analyses in nutrigenomic studies. Br J Nutr 93, 425-432.

57. Rajeevan MS, Ranamukhaarachchi DG, Vernon SD, et al. (2001) Use of real-time quantitative PCR to validate the results of cDNA array and differential display PCR technologies. Methods 25, 443-451.

58. Vergani L (2009) Metallothioneins in aquatic organisms: fish, crustaceans, molluscs and echinoderms. In Metal Ions in Life Sciences: Metallothioneins and Related Chelators, vol. 5, pp. 199-237 [A Sigel, H Sigel and RKO Sigel, editors]. Cambridge: Royal Society of Chemistry Publishing.

59. Kaji T, Yamamoto C, Tsubaki S, et al. (1993) Metallothionein induction by cadmium, cytokines, thrombin and endothelin-1 in cultured vascular endothelial cells. Life Sci 53, 1185-1191.

60. Kagi JHR \& Schaffer A (1988) Biochemistry of metallothionein. Biochemistry 27, 8509-8515.

61. Sato M \& Bremner I (1993) Oxygen free radicals and metallothionein. Free Radic Biol Med 14, 325-337.

62. Kang YJ (2006) Metallothionein redox cycle and function. Exp Biol Med 231, 1459-1467.

63. Farag AM, Stansbury MA, Hogstrand, et al. (1995) The physiological impairment of free-ranging brown trout exposed to metals in the Clark Fork River, Montana. Can J Fish Aquat Sci 52, 2038-2050.

64. Olsson P-E (1993) Metallothionein gene expression and regulation in fish. In Biochemistry and Molecular Biology of Fishes. vol. 2: Molecular Biology Frontiers, pp. 259-278 [PW Hochachka and TP Mommsen, editors]. Amsterdam: Elsevier.

65. Formigari A, Irato P \& Santon A (2007) Zinc, antioxidant systems and metallothionein in metal mediated-apoptosis: biochemical and cytochemical aspects. Comp Biochem Physiol C: Toxicol Pharmacol 146, 443-459.
66. Silacci P, Mazzolai L, Gauci C, et al. (2004) Gelsolin superfamily proteins: key regulators of cellular functions. Cell Mol Life Sci 61, 2614-2623.

67. Torti FM \& Torti SV (2002) Regulation of ferritin genes and protein. Blood 99, 3505-3516.

68. Pratt JM, Petty J, Riba-Garcia I, et al. (2002) Dynamics of protein turnover, a missing dimension in proteomics. $\mathrm{Mol}$ Cell Proteomics 1, 579-591.

69. Conrads KA, Yi M, Simpson KA, et al. (2005) A combined proteome and microarray investigation of inorganic phosphate-induced pre-osteoblast cells. Mol Cell Proteomics 4 1284-1296.

70. Kuo CC, Kuo CW, Liang CM, et al. (2005) A transcriptomic and proteomic analysis of the effect of CpG-ODN on human THP-1 monocytic leukemia cells. Proteomics 5, 894-906.

71. Sanden M, Krogdahl A, Bakke-McKellep AM, et al. (2006) Growth performance and organ development in Atlantic salmon, Salmo salar L. parr fed genetically modified (GM) soybean and maize. Aquacult Nutr 12, 1-14.

72. Flachowsky G, Chesson A \& Aulrich K (2005) Animal nutrition with feeds from genetically modified plants. Arch Anim Nutr 1, 1-40.

73. Woodward B, Young LG \& Lun AK (1983) Vomitoxin in diets for rainbow trout (Salmo gairdneri). Aquaculture 35, 93-101.

74. Sehata S, Kiyosawa N, Makino T, et al. (2004) Morphological and microarray analysis of T-2 toxin-induced rat fetal brain lesion. Food Chem Toxicol 42, 1727-1736.

75. Sehata S, Kiyosawa N, Sakuma K, et al. (2004) Gene expression profiles in pregnant rats treated with T-2 toxin. Exp Toxicol Pathol 55, 357-366.

76. El Golli E, Hassen W, Bouslimi A, et al. (2006) Induction of Hsp 70 in Vero cells in response to mycotoxins: cytoprotection by sub-lethal heat shock and by vitamin E. Toxicol Lett 166, 122-130.

77. Kouadio JH, Mobio TA, Baudrimont I, et al. (2005) Comparative study of cytotoxicity and oxidative stress induced by deoxynivalenol, zearalenone or fumonisin $\mathrm{B} 1$ in human intestinal cell line Caco-2. Toxicology 213, 56-65.

78. Sahu SC, Garthoff LH, Robl MG, et al. (2008) Rat liver clone9 cells in culture as a model for screening hepatotoxic potential of food-related products: hepatotoxicity of deoxynivalenol. J Appl Toxicol 28, 765-772.

79. Bodea GOD, Munteanu MC, Dinu D, et al. (2009) Influence of deoxynivalenol on the oxidative status of HepG2 cells. Rom Biotech Lett 14, 4349-4359.

80. Chowdhury SR, Smith TK, Boermans HJ, et al. (2005) Effects of feed-borne Fusarium mycotoxins on hematology and immunology of laying hens. Poultry Sci 84, 1841-1850.

81. Maresca M, Mahfoud R, Garmy N, et al. (2002) The mycotoxin deoxynivalenol affects nutrient absorption in human intestinal epithelial cells. $J$ Nutr 132, 2723-2731.

82. Vasatkova A, Krizova S, Adam V, et al. (2009) Changes in metallothionein level in rat hepatic tissue after administration of natural mouldy wheat. Int $J \mathrm{Mol} S c i \mathbf{1 0}$, 1138-1160.

83. Hunder G, Schümann K, Strugala G, et al. (1991) Influence of subchronic exposure to low dietary deoxynivalenol, a trichothecene mycotoxin, on intestinal absorption of nutrients in mice. Food Chem Toxicol 29, 809-814.

84. Bakan B, Melcion D, Richard-Molard D, et al. (2002) Fungal growth and Fusarium mycotoxin content in isogenic traditional maize and genetically modified maize grown in France and Spain. J Agric Food Chem 50, 728-731. 
85. Dowd PF (2000) Indirect reduction of ear molds and associated mycotoxins in Bacillus thuringiensis corn under controlled and open fiels conditions: utility and limitations. $J$ Econ Entomol 93, 1669-1679.

86. Papst C, Utz HF, Melchinger AE, et al. (2005) Mycotoxins produced by Fusarium spp. in isogenic Bt vs. non-Bt maize hybrids under European corn borer pressure. Agron J 97, 219-224

87. Munkvold GP, Hellmich RL \& Showers WB (1997) Reduced fusarium ear rot and symptomless infection in kernels of maize genetically engineered for european corn borer resistance. Phytopathol 87, 1071-1077.

88. Ostry V, Ovesna J, Skarkova J, et al. (2010) A review on comparative data concerning Fusarium mycotoxins in B maize and non-Bt isogenic maize. Mycotox Res $\mathbf{2 6}$, $141-145$.

89. Röhlig RM, Eder J \& Engel KH (2009) Metabolite profiling of maize grain: differentiation due to genetics and environment. Metabolomics 5, 459-477.

90. Harrigan GG, Stork LG, Riordan SG, et al. (2007) Impact of genetics and environment on nutritional and metabolite components of maize grain. I Agric Food Chem 55 , 6177-6185

91. Röhlig RM \& Engel K-H (2010) Influence of the input system (conventional versus organic farming) on metabolite profiles of maize (Zea mays) kernels. J Agric Food Chem 58, 3022-3030.

92. Zolla L, Rinalducci S, Antonioli P, et al. (2008) Proteomics as a complementary tool for identifying unintended side effects occurring in transgenic maize seeds as a result of genetic modifications. J Proteome Res 7, $1850-1861$
93. Boutigny A-L, Richard-Forget F \& Barreau C (2008) Natural mechanisms for cereal resistance to the accumulation of Fusarium trichothecenes. Eur J Plant Patbol 121, 411-423.

94. Hamzehzarghan H (2007) Metabolic profiling and multivariate analysis to phenotype cultivars of wheat varying in resistance to fusarium head blight. PhD thesis, Department of Plant Science, McGill University.

95. Stoop JMH, Williamson JD \& Mason Pharr D (1996) Mannitol metabolism in plants: a method for coping with stress. Trends Plant Sci 1, 139-144.

96. Ramachandran S, Fontanille P, Pandey A, et al. (2006) Gluconic acid: properties, applications and microbial production. Food Technol Biotechnol 44, 185-195.

97. Kaur R, Macleod J, Foley W, et al. (2006) Gluconic acid: an antifungal agent produced by Pseudomonas species in biological control of take-all. Phytochemistry 67, 595-604.

98. De Luis R, Pèrez MD, Sánchez L, et al. (2008) Kinetic and thermodynamic parameters for heat denaturation of Cry1A(b) protein from transgenic maize (Zea maize). J Food Sci 73, C447-C451.

99. ILSI (2007) Best Practices for the Conduct of Animal Studies to Evaluate Crops Genetically Modified for Output traits. Washington, DC: International Food Biotechnology Committee/International Life Sceinces Institute. http://www. ilsi.org/FoodBioTech/Documents/BestPractices2007.pdf.

100. EFSA (2006) Guidance document of the Scientific Panel on Genetically Modified Organisms for the risk assessment of genetically modified plants and derived food and feed. EFSA J 99, 1-100.

101. Tacon AGJ (1987) The Nutrition and Feeding of Farmed Fish and Shrimp - A Training Manual: 1. The Essential Nutrients. GPC/RLA/075/ITA, p. 117. Brasilia: Food and Agriculture Organization of the United Nations. 